\title{
O CÓDIGO ELEITORAL DE 1932 E AS ELEIÇÕES DA ERA VARGAS: UM PASSO NA DIREÇÃO DA DEMOCRACIA?*
}

The 1932 Electoral Code and the Vargas Era's elections: a step toward democracy?

El Código Electoral de 1932 y las elecciones de la Era Vargas: ¡un paso hacia la democracia?

JAQUELINE PORTO ZULINI ${ }^{\mathrm{I}^{* * *}}$
PAOLO RICCI ${ }^{\mathrm{I}{ }^{* * * *}}$

http://dx.doi.org/10.1590/S2178-14942020000300009

*Agradecemos à Fundação de Amparo à Pesquisa do Estado de São Paulo (FAPESP) o financiamento parcial desta pesquisa (Processo n. 2017/19828-0 e Processo n. 18/23060-2).

'Centro de Pesquisa e Documentação de História Contemporânea do Brasil, Fundação Getulio Vargas - Rio de Janeiro (RJ), Brasil.

**Professora de Ciência Política (jaqueline.zulini@fgv.br)

(1) https://orcid.org/0000-0001-6153-7328

"Departamento de Ciência Política, Universidade de São Paulo - São Paulo (SP), Brasil.

***Professor do Departamento de Ciência Política, Universidade de São Paulo (paolo.ricci.usp@gmail.com)

(1) https://orcid.org/0000-0003-2920-4536

Artigo recebido em 20 de abril de 2020 e aprovado para publicação em 7 de julho de 2020. 


\title{
RESUMo
}

Como interpretar o Código Eleitoral de 1932? Ele introduziu medidas consideradas fundamentais para ampliar a participação política e viabilizar a eleição das oposições, adotando voto secreto, representação proporcional, voto feminino, voto obrigatório e Justiça Eleitoral. A literatura costuma apontar o Código como um progresso das instituições brasileiras rumo à democracia. Esse artigo propõe uma interpretação alternativa. Analisando o contexto da concepção dessas regras e o impacto delas nas eleições de 1933 e 1934, argumentamos que o Código Eleitoral de 1932 atendeu aos interesses do governo autoritário que buscava legitimar a Revolução de 1930 nas urnas.

PALAVRAS-CHAVE: Código Eleitoral de 1932; Era Vargas; eleições; autoritarismo eleitoral; competição política

\begin{abstract}
How to interpret the Brazilian Electoral Code of 1932? It introduced measures considered fundamental to expand political participation and adopted the secret vote, proportional representation, women's suffrage, mandatory voting, besides creating an Electoral Court. The literature usually points to the Code as a progress made by Brazilian institutions toward democracy. This article proposes an alternative interpretation. Analyzing the context behind the design of these rules and their impact on the 1933 and 1934 elections, we argue that the 1932 Electoral Code served the interests of the authoritarian government that sought to legitimize the 1930 Revolution at the box office.
\end{abstract}

KEYWORDS: 1932 Brazilian Electoral Code; Vargas Era; elections; electoral authoritarianism; political competition

\section{RESUMEN}

¿Cómo interpretar el Código Electoral de 1932? Este código introdujo medidas consideradas fundamentales para expandir la participación política y permitir la elección de oposiciones, adoptando el voto secreto, la representación proporcional, el voto femenino, el voto obligatorio y la Justicia Electoral. La literatura generalmente apunta al Código como un progreso realizado por las instituciones brasileñas hacia la democracia. Este artículo propone una interpretación alternativa. Analizando el contexto del diseño de estas reglas y su impacto en las elecciones de 1933 y 1934, argumentamos que el Código Electoral de 1932 sirvió a los intereses del gobierno autoritario que buscó legitimar la Revolución de 1930 en las urnas.

PALABRAS CLAVE: Código Electoral de 1932; Era Vargas; elecciones; autoritarismo electoral; competencia política. 


\section{INTRODUÇÃO}

E m 24 de fevereiro de 1932, o Governo Provisório instaurado após a Revolução de 1930 e chefiado por Vargas decretou um Código Eleitoral para regular as eleições de 1933. Na época, o Código foi aclamado pelo então Ministro da Justiça, Mauricio Cardoso, como "carta de alforria do povo brasileiro" (Correio da Manhã, 1932: 4). A imprensa também o festejou porque viu nele a possibilidade da "reintegração do país no regime legal" (A Noite, 1932: 1), associando-o a um projeto nacional "rumo à constitucionalização" (A Federação, 1932: 3). 0 conteúdo das medidas incorporadas pelo Código representa um marco na história das instituições eleitorais brasileiras: adotaram-se o voto secreto, a representação proporcional, o voto feminino e o voto obrigatório, além de se terem criado a Justiça Eleitoral e a representação das classes profissionais.

Como interpretar a organização de um Código Eleitoral desse porte? Eis a questão central deste artigo. A tendência tem sido avaliá-lo tanto pela percepção mais genérica de que as novas regras eleitorais representavam um "progresso" em relação à Primeira República (Kinzo, 1980; Leal, 1997; Nicolau, 2012; Sadek, 2010) quanto pelo entendimento de se configurar um progresso rumo à democracia (Lamounier, 2005; Schwarcz e Starling, 2015). Não se trata de negar os avanços formais desenhados pela reforma, mas de contextualizá-los. Tais interpretações podem até ser válidas para dar fundamento teórico à ideia de que houve uma mudança no governo representativo, mas não é possível desconsiderar o que concretamente estava em jogo na época. Estudos conduzidos sobre governos autoritários mostram que a decisão de reescrever as regras eleitorais não coincide necessariamente com o interesse real dos governantes em tornar o regime mais aberto e participativo (Gandhi, 2009). Convém considerar a possibilidade de se interpretar o Código Eleitoral de 1932 à luz da imprescindível legitimação visada pelo Governo Provisório para se firmar como regime distinto do seu predecessor. Nesse propósito, exploramos duas razões para a adoção do Código Eleitoral, desconectadas de intenções democráticas. A primeira refere-se à derrota do grupo de revolucionários interessado em manter um governo autoritário sem eleições e à vitória dos que idealizaram a legitimação do novo regime defendendo o governo representativo. A segunda diz respeito à manutenção de uma competição política que continua apelando à fraude eleitoral. Dados introduzidos na segunda seção revelam como o Governo Provisório estimulou a ação direta dos interventores na organização de partidos estaduais, buscando melhor desempenho eleitoral dos revolucionários. A terceira seção reporta evidências para as eleições de 1933 do recurso aos instrumentos de controle do eleitor e dos agentes envolvidos no processo eleitoral, repetindo a falta de imparcialidade tão criticada na Primeira República. Diante de tudo isso, 
o artigo conclui que o regime inaugurado pela Revolução de 1930 pode ser enquadrado na categoria dos autoritarismos eleitorais (Gandhi, 2009). A expressão é facilmente explicável: de um lado existiam novas regras eleitorais conferindo legitimidade aos novos governantes e, de outro, a interferência maciça do governismo sobre o processo eleitoral.

\section{LEGITIMANDO O NOVO REGIME POR MEIO DE ELEIÇÕES}

$\mathrm{H}$

á pelo menos duas décadas a historiografia fez uma autocrítica quanto ao endosso me-

cânico do discurso dos ideólogos autoritários do Estado Novo. Reconheceu-se que o empenho dos revolucionários em positivar a imagem do "novo" Estado às custas da desconstrução da experiência política anterior, partindo da criação da emblemática alcunha de República "velha" em meados de 1931, contaminou a forma como a literatura clássica retratou a Primeira República (Gomes e Abreu, 2009). A conscientização dos historiadores sobre o peso da ideologia embutida nos escritos dos revolucionários que serviram como fontes para intérpretes posteriores seguirem reproduzindo diagnósticos pessimistas do passado republicano refletiu a influência da chamada Nova História. Aquela máxima de Jacques Le Goff (1990), segundo a qual todo "documento é monumento" no sentido de resultar do esforço de se impor ao futuro uma pretensa imagem do passado, inspirou a relativização de alguns estereótipos da Primeira República'. Ainda é incipiente uma discussão historiográfica análoga no caso dos anos 1930-1937, cuja cobertura continua amplamente respaldada pelo discurso político da época e o conhecido mantra da necessidade de moralização eleitoral entoado pelos revolucionários como justificativa para o golpe de 1930 e seus desdobramentos. Contudo, o Código Eleitoral materializou, antes, a derrota de uma visão diferente, que preferia manter um governo autoritário sem eleições.

No imediato pós-revolução, várias correntes disputavam um projeto de Estado para o Brasil. Para simplificar o contexto, podemos qualificá-lo em termos dicotômicos. De um lado estavam os tenentes, unidos pela defesa da centralização das funções administrativas e da permanência da ditatura "como meio de sanear costumes e de redefinir os ideais da nação" (Gomes, 1980: 28)². De outro, encontravam-se as elites políticas estaduais, em sua maioria velhas oligarquias republicanas, que lutavam para manter a estrutura federativa e o governo representativo. A aprovação do Código Eleitoral de 1932 não deve ser lida como uma vitória da segunda corrente sobre a primeira. Tratou-se da decisão tomada pelo Governo Provisório de constitucionalizar o regime visando à legitimação popular. Na prática, faz mais sentido considerar o Código como a "grande obra" do Poder Discricionário exercido provisoriamente por Vargas (Lopes, 2019). 
Governantes autoritários podem reformar as instituições buscando legitimar-se perante o povo (Morgenbesser, 2014; Schedler, 2006), mas sem por isso aceitar um jogo democrático. A decisão de introduzir novas regras levaria em conta as consequências de não fazê-lo (Gandhi, 2009). No caso do Governo Provisório, defender uma mudança nas regras eleitorais condizia com a missão emblemática de renovação das instituições representativas diretamente encampada desde a campanha da Aliança Liberal e apropriada pelo discurso revolucionário para justificar o golpe de 1930. Desertar do compromisso de moralizar as eleições não significava apenas perder credibilidade popular, mas também se indispor com parte das elites que apoiaram a Revolução como uma fase transitória para preparar a restauração liberal.

A vitória da corrente interessada em legitimar o regime pela via eleitoral foi gradual e ocorreu por etapas. 0 ano de 1929 marcou a primeira delas, associada à campanha presidencial. Durante o lançamento da candidatura, Vargas anunciou que seu programa de governo visaria:

- testar "por experiência a obrigatoriedade do voto";

- dar garantia efetiva ao voto secreto;

- incorporar o " sistema da representação proporcional, adotada, hoje em dia, pelas legislações mais avançadas do mundo" (Jornal do Comércio, 1929: 4).

Na prática, tópicos que retomavam propostas erguidas havia anos, frequentemente chamadas em causa para legitimar a mudança no padrão eleitoral.

0 voto obrigatório emergia como solução para a alta abstenção que caracterizava as eleições na Primeira República. Em suas páginas costumeiramente críticas ao modo de se votar, O Malho clamava em 1924: "Todo cidadão que se preze deve alistar-se eleitor! Ao voto obrigatório! Avante!". Também o voto secreto era quase um senso comum, considerado o passe para um possível mundo onde o eleitor votaria livre de pressões (Schlegel e Nóbrega, 2019). Quando a Aliança Liberal encampou o voto secreto, retomou a defesa pela cabine de votação: um ambiente fechado onde o eleitor poderia, em segredo, colocar em um envelope a cédula do partido de sua preferência ${ }^{3}$. A fórmula eleitoral frequentemente ocupava os noticiários dos jornais. Para as eleições legislativas, comentaristas e políticos da época bradavam a adoção da representação proporcional, retomando os argumentos de Joaquim Francisco de Assis Brasil, o célebre autor de Democracia representativa (1893), em defesa da representação das minorias. Por fim, existiam associações organizadas desde o Império que se mobilizavam em prol do voto feminino (Pinto, 2003).

A segunda etapa que definiu o processo de apropriação das ideias reformistas reivindicadas desde a Primeira República foi justamente a criação de uma comissão encarregada 
de redigir as novas regras eleitorais. 0 Decreto $n^{0}$ 19.684/1931 nomeou para essa comissão o próprio Assis Brasil, João Chrysostomo da Rocha Cabral e Mário Pinto Serva — todos especialistas em matéria eleitoral. Cabral havia publicado Systemas eleitoraes do ponto de vista da representação proporcional das minorias em 1929, e Serva habitualmente assinava artigos no Diário Nacional em prol das reformas e ainda lançara 0 voto secreto ou a organização de Partidos Nacionais em 1927. Considerando-se os precedentes, a composição da comissão sinalizava claramente para uma posição reformista.

Observa-se no andamento da reforma eleitoral que daria vida ao Código de 1932 a terceira etapa do processo que culminou na vitória do projeto reformista. A princípio, os trabaIhos da comissão estenderam-se. 0 Código Eleitoral foi outorgado a 24 de fevereiro de 1932, após mais de um ano de instalação da comissão. Nesse período de elaboração das novas normas eleitorais, a maioria dos jornais da época apoiava a necessidade das reformas. Aliás, uma das críticas principais direcionada à comissão era da demora da edição de uma lei que permitisse a reconstitucionalização do país. A comissão Assis-Cabral-Pinto apresentou um anteprojeto em agosto de 1931, inspirado na lei eleitoral do Uruguai (a Lei de Registro Cívico Nacional, de 1924). A imprensa fez questão de enfatizar o ponto: "Dos duzentos e vinte e dois artigos da lei uruguaia mais de cento e oitenta foram traduzidos para o anteprojeto brasileiro" (Correio da Manhã, 1931b: 4). 0 texto foi duramente criticado por sua complexidade e considerado de difícil execução, ficando engavetado até dezembro daquele ano, quando um defensor da reconstitucionalização do país assumiu o Ministério da Justiça no lugar de Oswaldo Aranha. Trata-se de Mauricio Cardoso que, dois dias após a posse, indicou mais sete jurisconsultos para integrarem a comissão de reforma eleitoral (Correio da Manhã, 1931a: 1). Dali em diante, sem a presença de Assis Brasil, procedeu-se a uma revisão célere e substantiva daquele anteprojeto de reforma eleitoral apresentado em 1931. Cerca de dois meses depois, a comissão finalizou seu trabalho e Vargas pôde outorgar o Código Eleitoral. Vale frisar: isso se deu a 24 de fevereiro de 1932, antes de São Paulo deflagrar a Revolução Constitucionalista. A outorga do Código atestava a derrota de quem pregava contra a convocação de eleições para a Constituinte. Nomeadamente, uma derrota para os tenentistas que continuavam engajados pela manutenção da ditadura.

\section{ORGANIZANDO A ELEIÇÃO: CRIANDO PARTIDOS E MOBILIZANDO ELEITORES}

Ieições são um risco também em regimes autoritários, que precisam elaborar estratégias para
suplantar uma possível incerteza dos resultados e condicionar a própria permanência no poder. 
Nesta seção tratamos da primeira estratégia adotada pelo Governo Provisório para enfrentar as disputas à Constituinte de 1933 e, sucessivamente, às Assembleias Legislativas estaduais de 1934, a saber: a organização de novos partidos criados pelos interventores (Gomes, 1980; Pandolfi, 1980). O Governo Provisório esperava que os interventores encabeçassem o processo de organização partidária (Pandolfi, 1980: 380), alistando o maior número de eleitores e assegurando o maior comparecimento possível no dia da eleição para viabilizar a vitória dos revolucionários nas urnas.

No caso das eleições constituintes, o processo de organização dos partidos políticos foi abrupto. A menos de três meses da outorga do Código Eleitoral, foi fixada a data das eleições que definiriam os 214 deputados constituintes para 3 maio de $1933^{4}$. Entretanto, os preparativos para as eleições atrasaram por causa do levante da Revolução Constitucionalista. A maioria dos partidos surgiu depois do fim desse conflito, constituindo-se a poucos meses de maio de 1933. 0 comprometimento dos interventores com as demandas do Governo Provisório em relação ao estabelecimento dos núcleos partidários de defesa da Revolução nos estados variou bastante, embora na maioria dos casos se tenha formado um partido aglutinando os revolucionários de 1930. Parte dos interventores desempenhou papel mais proativo no processo de criação dos partidos. Os jornais cobriam diariamente esse processo. Em janeiro, 0 Diário de Notícias anunciava que se estavam formando novos partidos "sob o olhar vigilante dos interventores e nos moldes dos 'partidos situacionistas'" (Diário de Notícias, 1933a: 2). Outros interventores preferiram manter certa distância e uma minoria não conseguiu centralizar a iniciativa, perdendo completamente o controle dos rumos das facções políticas sob seu território. Alguns exemplos ilustram bem as diferentes reações.

Primeiramente, vale retomar a postura de dois interventores que decidiram ter protagonismo na organização partidária. Juraci Magalhães, interventor da Bahia (1931-1935), foi um deles. Cearense e militar, Magalhães assumiu um estado de poucos adeptos da revolução e sofreu a oposição do Partido Republicano da Bahia, que vocalizava a demanda local por um interventor baiano e civil. Para dar conta da responsabilidade de alavancar um partido a tempo das eleições constituintes, o interventor apelou para uma composição com as antigas oligarquias do interior do estado. Em fins de janeiro de 1933, acercou-se do apoio de representantes políticos de vinte municípios do vale do rio São Francisco, que assinaram o chamado "pacto sertanejo" em Juazeiro, para sinalizar o desejo de "esquecer completamente todas as velhas dissensões partidárias ou pessoais, acatando a vontade do tenente Juraci Magalhães" (Diário da Noite, 1933: 12). Por trás dessa coligação, semeava-se o Partido Social Democrático da Bahia, fundado pouco tempo depois sob a égide do interventor, considerado seu capitão. Tanta confiança na lealdade dos seus correligionários levou Magalhães até a rechaçar o adiamento das eleições constituintes, cogitado justamente por conta da pausa que a Revo- 
lução Constitucionalista significou para os preparativos eleitorais. Questionado, o interventor foi taxativo: "Não demos aos adversários um pretexto de que eles tanto carecem. As eleições vão realizar-se a 3 de Maio. A vitória da Revolução vai ser esmagadora. A opinião nacional está inteiramente ao nosso lado: entre o presente e o passado, escolhe o presente" (Jornal do Comércio, 1933: 4).

O outro caso diz respeito à experiência do interventor de Pernambuco, Carlos de Cavalcanti Lima (1930-1934). Proprietário do Diário da Manhã publicado no estado, Cavalcanti Lima engajou-se no propósito de assumir a vanguarda da organização partidária em Pernambuco e fez do jornal uma espécie de diário oficial da interventoria, também para arregimentar eleitores ao partido que organizara, o Partido Social Democrático de Pernambuco. Desde 18 de janeiro de 1933, o seguinte cabeçalho passou a compor sucessivas edições do jornal:

CIDADÃOS! A defesa de vossos direitos políticos, a resistência em prol dos legítimos interesses da sociedade brasileira, estão em vosso comparecimento às eleições de 3 de Maio próximo. Se a Revolução iniciada em 1930 vos assegurou livre determinação política, abrindo novos horizontes aos destinos nacionais, a Evolução, que não pára, vos garantirá a continuidade dessa conquista. Alistai-vos eleitores do Partido Social Democrático de Pernambuco, cumprindo assim vosso dever e sustentando os ideais revolucionários triunfantes. (Sede do Partido: Avenida Rio Branco, 126, $1^{\circ}$ andar) (Diário da Manhã, 1933: 3, grifos do original).

Assim como Juraci Magalhães, Cavalcanti Lima também afastou a possibilidade de adiamento das eleições constituintes, enfatizando a importância de se cumprir com o "compromisso formal e solene que manda realizar as eleições constituintes em maio próximo (Diário da Manhã, 1933: 3) .

Da parte daqueles interventores que buscaram manter atitude mais neutra e distante do processo de organização partidária, observa-se nítida discordância ideológica quanto aos propósitos da Revolução. A posição que ocupavam deveria ser transitória e descomprometida com qualquer militância partidária, exatamente para assegurar a ocorrência de eleições constituintes sob um ambiente livre de fraudes e coação governamental, tão criticadas pelos revolucionários como ponto alto da desmoralização do passado eleitoral republicano. Mais dois casos ajudam a entender o ponto. Um deles refere-se ao comportamento de Carneiro de Mendonça, interventor do Ceará (1931-1934). Até o jornal criado pelo Governo Provisório para vocalizar os objetivos da Revolução admitiu que, mesmo com a fundação de um partido apoiador do seu governo por iniciativa dos elementos liberais e revolucionários do estado, entre eles a corrente liderada pelo ex-interventor Fernandes Távora, Carneiro de Mendonça manteve "intransigentemente o seu propósito de se alhear da política", esquivando-se "de qualquer influência nesse movimento de nucleação de forças políticas" (0 Radical, 1933a: 12). 
Tudo não passaria de um conflito entre a orientação oficial para os interventores promoverem a formação de partidos nos estados e as convicções pessoais de Carneiro de Mendonça:

Essa atitude [de Carneiro de Mendonça] não implica de nenhum modo discordância com os elementos revolucionários que tiveram a iniciativa dessa arregimentação partidária. Corresponde, sim, a um ponto de vista pessoal [...], o sr. Carneiro de Mendonça julga do seu dever, por força da própria coerência das suas atitudes, conservar-se, até o termo natural da sua missão transitória, à frente dos destinos do Estado, estranho a qualquer formação partidária (0 Radical, 1933a: 12).

Retrata-se na mesma situação Maynard Gomes, interventor de Sergipe (1930-1935). Fiel aos seus princípios, ele teria preferido "colocar o governo acima e alheio às competições partidárias" (Jornal do Brasil, 1933: 8). Ainda assim, tanto em Sergipe como no Ceará um partido estadual acabou aglutinando os revolucionários de 1930 e apoiando o interventor em exercício, funcionando, na prática, como o partido do interventor.

Por fim, apenas dois estados se encontram naquela situação mais rara na qual os interventores não conseguiram centralizar a organização de partidos "oficiais", isto é, organizados para funcionar como paladinos da Revolução nos estados. Trata-se do Maranhão e do Rio de Janeiro. 0 controle da política maranhense se revelou problemático para o Governo Provisório desde a Revolução. Indicativo disso era o fato de Vargas ter nomeado outros três interventores antes de chegar a Seroa da Mota (1931-1933), que administrou o estado durante os preparativos para a Constituinte. Seroa da Mota teve de lidar com o facciosismo e acabou incapaz de assumir as rédeas de um partido oficial no Maranhão, desafiado pelo ex-interventor Reis Perdigão (1930-1931), que chamou para si a responsabilidade de criar o Partido Revolucionário Maranhense (0 Imparcial, 1931: 1). No Rio de Janeiro, o interventor Ari Parreiras (1931-1935) também não conseguiu liderar a formação de um partido que unificasse os revolucionários no estado. Parreiras foi um dos muitos líderes tenentistas que compareceram à solenidade de fundação da União Cívica Nacional (UCN), a coligação integrada pelas correntes revolucionárias com o propósito de fomentar a instauração de um partido nacional (Correio da Manhã, 1933a: 3). Fazia cerca de três meses que o interventor buscava promover uma política de acomodação dos revolucionários de diversas matizes do estado em torno de um eixo comum, chegando a convocar quarenta deles para uma reunião destinada a eleger "uma comissão de cinco membros com a incumbência de organizar uma facção política, da qual o interventor fluminense, como administrador, seria o mandatário" (Diário de Notícias, 1933b: 3). Nasceu, assim, o Partido Socialista Brasileiro que, no entanto, escanteou a interventoria a ponto de Parreiras não apadrinhar nenhum dos partidos fundados no estado. 
Cabe analisar alguns dados para se poder dimensionar o quanto o Governo Provisório foi bem-sucedido na estratégia de contar com os partidos criados pelos interventores para concorrer às eleições constituintes de 1933 e, posteriormente, às eleições de 14 de outubro de 1934, realizadas sob as mesmas regras eleitorais para selecionar os novos deputados federais e os componentes das assembleias constituintes estaduais. A Tabela 1 identifica o nome dos partidos dos interventores e seu respectivo desempenho eleitoral em termos do percentual de cadeiras conquistadas nas eleições de 1933 e 1934. Considerou-se como partido do interventor aquele partido organizado diretamente pelo interventor estadual em exercício (a exemplo

Tabela 1 - Desempenho eleitoral dos partidos dos interventores nas eleições de 1933 e 1934

\begin{tabular}{|c|c|c|}
\hline \multirow{2}{*}{ ESTADO } & \multicolumn{2}{|c|}{ ELEIÇÕES DE 3/5/1933 } \\
\hline & PARTIDO DO INTERVENTOR & CADEIRAS CONQUISTADAS (\%) \\
\hline$A C$ & Legião Autonomista Acreana & 0 \\
\hline $\mathrm{AL}$ & Partido Nacional de Alagoas & 100 \\
\hline AM & União Cívica Amazonense & 75 \\
\hline BA & Partido Social Democrático da Bahia & 90,9 \\
\hline CE & Partido Social Democrático do Ceará & 40 \\
\hline DF & Partido Autonomista do Distrito Federal & 60 \\
\hline ES & Partido Social Democrático do Espírito Santo & 75 \\
\hline GO & Partido Social Republicano de Goiás & 100 \\
\hline MA & - & - \\
\hline MG & Partido Progressista & 83,8 \\
\hline MT & Partido Liberal Mato-Grossense & 75 \\
\hline PA & Partido Liberal do Pará & 100 \\
\hline PB & Partido Progressista da Paraíba & 100 \\
\hline PE & Partido Social Democrático de Pernambuco & 88,2 \\
\hline $\mathrm{PI}$ & Partido Nacional Socialista & 75 \\
\hline PR & Partido Social Democrático do Paraná & 75 \\
\hline RJ & - & - \\
\hline RN & Partido Social Nacionalista & 25 \\
\hline RS & Partido Republicano Liberal & 81,3 \\
\hline SC & Partido Liberal Catarinense & 75 \\
\hline SE & Partido de Republicano de Sergipe & 75 \\
\hline SP & Partido da Lavoura & 9,1 \\
\hline
\end{tabular}

Continua... 
Tabela 1 - Continuação

\begin{tabular}{|c|c|c|c|}
\hline \multirow[b]{2}{*}{ Estado } & \multicolumn{3}{|c|}{ ELEIÇÕES DE 14/10/1934 } \\
\hline & PARTIDO DO INTERVENTOR & $\begin{array}{c}\text { CADEIRAS } \\
\text { CONQUISTADAS } \\
\text { NA CD }(\%)\end{array}$ & $\begin{array}{c}\text { CADEIRAS } \\
\text { CONQUISTADAS NAS } \\
\text { AsSEMBLEIAS (\%) }\end{array}$ \\
\hline$A C$ & Legião Autonomista Acreana & 0 & Não aplica* \\
\hline $\mathrm{AL}$ & Partido Republicano de Alagoas & 75 & 80 \\
\hline AM & Partido Popular do Amazonas & 100 & 80 \\
\hline BA & Partido Social Democrático da Bahia & 70,8 & 69 \\
\hline CE & Partido Social Democrático do Ceará & 36,4 & 40 \\
\hline DF & Partido Autonomista do Distrito Federal & 80 & 83,3 \\
\hline ES & Partido Social Democrático do Espírito Santo & 75 & 64 \\
\hline GO & Partido Social Republicano de Goiás & 75 & 66.7 \\
\hline MA & Partido Social Democrático do Maranhão & 28,6 & 43,3 \\
\hline MG & Partido Progressista & 71,1 & 70,8 \\
\hline MT & Partido Liberal Mato-Grossense & 25 & 45,8 \\
\hline PA & Partido Liberal do Pará & 77,8 & 70 \\
\hline PB & Partido Progressista da Paraíba & 100 & 90 \\
\hline PE & Partido Social Democrático de Pernambuco & 78,9 & 66,7 \\
\hline $\mathrm{Pl}$ & Partido Nacional Socialista & 80 & 70,8 \\
\hline$P R$ & Partido Social Democrático do Paraná & 66,7 & 66,7 \\
\hline RJ & - & - & - \\
\hline RN & Aliança Social & 40 & 84 \\
\hline RS & Partido Republicano Liberal & 70 & 65,6 \\
\hline SC & Partido Liberal Catarinense & 66,7 & 54,8 \\
\hline SE & Partido Republicano de Sergipe & 25 & 46,7 \\
\hline SP & Partido Constitucionalista & 64,7 & 60 \\
\hline
\end{tabular}

*O Território do Acre elegeu deputados à Assembleia Nacional Constituinte e deputados federais em 1934, mas não tinha uma assembleia estadual em 1934; CD: Câmara dos Deputados.

Fonte: Tribunal Superior Eleitoral (1933; 1934).

dos casos baiano e pernambucano supracitados), ou que aglutinava revolucionários apoiadores da interventoria (situações como as do Ceará e de Sergipe).

Os dados revelam dois resultados importantes para qualificar o desempenho eleitoral dos revolucionários nas urnas. Em primeiro lugar, destaca-se um padrão de continuidade do partido do interventor em 1934, sob a mesma nomenclatura criada em 1933, observada em 16 das 22 interventorias. Isso significa que a maioria dos interventores fez jus às expectativas 
do Governo Provisório e logrou a construção de agrupamentos políticos estáveis, até mesmo em uma conjuntura adversa, considerando-se a alta rotatividade dos interventores na época (Pandolfi, 1980). Em segundo lugar, os dados mostram a variação no desempenho eleitoral dos partidos dos interventores. Tanto em 1933 quanto em 1934, a maioria desses partidos cumpriu o esperado e fez mais da metade das cadeiras que disputou. De fato, raras vezes os partidos dos interventores perderam as eleições. Foi o caso do Acre (em 1933 e 1934), do Ceará (1933 e 1934), do Maranhão (1934), do Mato Grosso (1934), do Rio Grande do Norte (1933 e 1934), de São Paulo (1933) e de Sergipe (1934). 0 insucesso nesses casos deve ser mais bem entendido. Para além dos casos citados em que o interventor se esquiva da disputa partidária, é fundamental explorar a força das oposições. Talvez o caso mais claro seja o do Ceará, em que a Liga Eleitoral Católica (LEC), vinculada à Igreja Católica, vence as duas eleições nacionais ${ }^{6}$. Entretanto, há uma inovação notável perante o padrão da Primeira República: as oposições conseguem eleger alguns representantes. Assim, não se reproduz aquela exclusão das oposições típica do esquema das "bancadas unânimes" arquitetado pela política dos governadores e tão condenado pelos próceres da representação proporcional (Ricci e Zulini, 2014) ${ }^{7}$.

A pergunta imediata que se coloca diante dessas vitórias parciais dos partidos dos interventores é o que estaria por trás delas. Considerando-se que a literatura normalmente aponta o caráter mais livre das eleições na Era Vargas em comparação com a Primeira República, uma hipótese a se aventar interpretaria as vitórias dos partidos dos interventores como produtos de processos eleitorais com maior participação eleitoral e menor compressão governamental. Afinal, o Código Eleitoral de 1932 criou incentivos institucionais para concretizar ambas as características, na medida em que estabeleceu o alistamento obrigatório na expectativa de diminuir a abstenção, e adotou também o voto secreto junto com a Justiça Eleitoral, visando suplantar os tradicionais mecanismos de pressão sobre o eleitorado. Avaliemos, por enquanto, o contexto da participação eleitoral, deixando para a terceira seção a questão das condições do exercício do voto.

Quando o Código introduziu o alistamento obrigatório, estabeleceu para ele duas possibilidades diferentes e criou exigências sem precedentes no Brasil. Quanto às possibilidades, ficou definido que o alistamento poderia ser realizado ex officio ou por iniciativa do cidadão. No primeiro caso, os chefes das repartições de determinadas categorias profissionais (magistrados, professores, comerciantes, reservistas do exército, liberais com diploma científico) eram obrigados a fornecer para o juiz eleitoral a lista dos cidadãos qualificáveis ex officio informando a profissão, a nacionalidade brasileira, a idade e o endereço de residência desses cidadãos. Tratava-se de um tipo de alistamento mais centralizado, pois se dava em grupo, 
mantendo-se o controle sobre determinadas categorias profissionais. Os chefes de repartições funcionavam como um atalho, pois as suas declarações quanto às características dos funcionários tinham autoridade legal. No segundo caso, o alistamento era individual e cada cidadão interessado em se tornar eleitor precisava requisitar a sua qualificação eleitoral. Isso significa que o cidadão precisava provar a maioridade, a nacionalidade brasileira, estar quite com 0 serviço militar e ainda reconhecer a sua firma. Para finalizar o processo de alistamento, todos os cidadãos qualificados ex officio ou por conta própria deveriam comparecer ao cartório eleitoral e entregar pessoalmente três fotografias. Na época, itens de luxo e que até então não faziam parte das exigências para o alistamento no Brasil.

Durante a elaboração do futuro Código Eleitoral, os jornais apontavam justamente o custo criado pelas novas medidas de alistamento e temiam que elas atrasassem a restauração liberal. O Jornal do Brasil, por exemplo, condenou veementemente o formato do alistamento: "o que pode haver de mais caro e complexo, em matéria de organização eleitoral" (Jornal do Brasil, 1931: 5). Até entre os autores do anteprojeto do Código Eleitoral não havia consenso quanto ao modo de se fazer o alistamento. Mário Pinto Serva se afastou dos trabalhos da comissão por discordar da opinião de Assis Brasil e João Cabral nesse ponto e chegou a afirmar em entrevista que o alistamento proposto pelos seus pares era "inviável [...], impondo uma despesa de mais de cem mil contos por ano" (Jornal do Brasil, 1931: 5).

Será que as novas regras de alistamento mudaram algo em comparação ao passado na Primeira República? Para responder à pergunta, exploramos alguns dados sobre a natureza do eleitorado, que permitem comparar as eleições de 1933 e 1934 com a última e mais renhida eleição da Primeira República, ocorrida em 1930. A Tabela 2 apresenta as taxas de crescimento do eleitorado alistado para as eleições de 1933 e 1934 em relação ao eleitorado alistado em 1930. Taxas acompanhadas de sinal negativo significam que o tamanho do eleitorado alistado diminuiu. Além disso, a tabela reporta a diferença do comparecimento eleitoral em pontos percentuais de 1933 e 1934, sempre com referência a 1930. Diferenças de comparecimento eleitoral com sinal negativo indicam diminuição do comparecimento eleitoral em pontos percentuais.

Os dados retratam dois cenários relevantes. Em primeiro lugar, observa-se que o eleitorado diminuiu entre a Primeira República e a Era Vargas. Nas eleições constituintes de 1933 houve recrudescimento de quase 50\% do eleitorado em relação a 1930. A princípio, uma situação contraintuitiva, considerando-se que o Código Eleitoral de 1932 adotou o alistamento obrigatório e o voto feminino (por si só, uma inovação com capacidade de dobrar o eleitorado). Contudo, o encolhimento do eleitorado em 1933 teve conexão direta com o estouro da Revolução Constitucionalista, que retardou a organização dos tribunais eleito- 
Tabela 2 - Crescimento do eleitorado e diferença no comparecimento eleitoral entre a Primeira República e a Era Vargas

\begin{tabular}{|c|c|c|c|c|}
\hline Estados * & $\begin{array}{c}\text { CRESCIMENTO DO } \\
\text { ELEITORADO EM } 1933 \\
(\text { EM \% } \%)^{* *}\end{array}$ & $\begin{array}{c}\text { CRESCIMENTO DO } \\
\text { ELEITORADO EM } 1934 \\
(\text { EM \% } \%)^{* *}\end{array}$ & $\begin{array}{c}\text { DifERENÇA NO } \\
\text { COMPARECIMENTO EM } \\
1933(\text { EM \% } \%)^{* *}\end{array}$ & $\begin{array}{c}\text { DifERENÇA NO } \\
\text { COMPARECIMENTO EM } \\
1934\left(\text { EM \% } \%{ }^{* *}\right.\end{array}$ \\
\hline $\mathrm{AL}$ & $-33,85$ & $-3,10$ & 25,0 & 1,7 \\
\hline AM & $-77,32$ & $-48,92$ & 49,3 & 53,9 \\
\hline BA & $-59,98$ & $-18,54$ & 4,5 & 7,5 \\
\hline CE & $-75,59$ & $-39,53$ & 9,2 & $-1,6$ \\
\hline DF & $-41,35$ & $-5,98$ & 44,1 & 36,6 \\
\hline ES & $-38,96$ & 6,75 & 17,6 & 20,5 \\
\hline GO & $-32,59$ & 40,93 & $-3,2$ & $-9,2$ \\
\hline MA & $-79,72$ & $-25,52$ & 14,9 & 4,5 \\
\hline MT & $-59,87$ & $-0,05$ & 2,3 & 13,6 \\
\hline MG & $-51,76$ & $-17,79$ & 27,9 & 16,6 \\
\hline PA & $-68,43$ & $-49,07$ & 12,3 & 3,4 \\
\hline PB & $-52,13$ & $-16,97$ & 16,2 & $-16,5$ \\
\hline$P R$ & $-65,33$ & $-36,11$ & 19,8 & 20,7 \\
\hline$P E$ & $-40,84$ & 4,85 & 18,6 & 13,3 \\
\hline $\mathrm{Pl}$ & $-68,42$ & 23,65 & 22,4 & 15,0 \\
\hline RJ & $-58,62$ & $-5,61$ & 28,2 & 26,0 \\
\hline RN & $-29,28$ & 76,81 & 25,1 & 14,4 \\
\hline RS & $-37,14$ & $-11,02$ & 3,2 & $-13,6$ \\
\hline SC & $-51,98$ & 17,90 & 11,3 & 23,0 \\
\hline SP & $-42,11$ & 3,45 & 16,4 & 6,9 \\
\hline SE & $-18,33$ & 58,95 & 25,7 & 24,3 \\
\hline$B R$ & $-50,21$ & $-9,78$ & 18,7 & 10,3 \\
\hline
\end{tabular}

* Excluímos o Acre porque durante a Primeira República não havia eleições para esse território, sob administração do estado do Amazonas. ** Os indicadores de 1933 e 1934 foram calculados fazendo referência às eleições de 1930.

Fonte: Os números brutos relativos ao eleitorado alistado em 1930 encontram-se no Diário do Congresso Nacional, de 21 de maio de 1930, p. 545. Para 1933 e 1934, as informações constam dos boletins do Tribunal Superior Eleitoral de 13 de julho de 1934 e 22 de fevereiro de 1936, respectivamente.

rais e dos próprios partidos políticos, sobrando pouco tempo para se alistarem os eleitores. Como antecipado, entrou em consideração a hipótese de adiar as eleições constituintes sob 0 argumento da escassez de tempo hábil para se promover o recadastramento eleitoral nos 
moldes das novas regras criadas em 1932. No final, o Governo Provisório preferiu afrouxar as regras de alistamento estabelecidas pelo Código Eleitoral e editou o Decreto $n^{\circ} 22.168$, em dezembro de 1932. As medidas de emergência apontadas no decreto estendiam o alistamento ex officio aos membros de sindicatos registrados pelo Ministério do Trabalho (art. $2^{\circ}$, letra h) e dispensavam a coleta de impressões digitais onde não houvesse serviço de identificação datiloscópica, para efeito de apresentação tanto dos requerimentos ex officio (art. $4^{\circ}, \S 2^{\circ}$ ) quanto dos requerimentos a pedido do próprio cidadão (art. $6^{\circ}$, inciso I). Estes últimos ainda ficavam desobrigados de prova de quitação do serviço militar (art. 5, parágrafo único, letra a). Mesmo assim, não foi possível alistar eleitores em proporções equivalentes à de 1930. Os dados para as eleições de 1934 mostram que houve aumento dos alistados, mas em número ainda inferior ao de 1930.

Daí o segundo cenário relevante revelado pelos dados, que diz respeito ao aumento do comparecimento eleitoral na Era Vargas com relação a 1930. Houve acréscimo de 18,7 pontos percentuais em 1933, enquanto em 1934 o aumento foi de 10,3 pontos percentuais relativamente a 1930. Isso mostra que, embora existissem menos eleitores alistados para as eleições de 1933 e 1934, eles tenderam a comparecer mais para votar. Cabe pontuar que provavelmente os valores do comparecimento relativos a 1930 se encontram superestimados. A tabela anterior valeu-se de dados oficiais, entretanto, parece que as chamadas eleições "a bico de pena", no sentido de que os resultados eleitorais eram fabricados na ponta da caneta (da "pena") quando, de fato, ninguém votou, configuraram o padrão da Primeira República. Em síntese, a diferença entre a Primeira República e a Era Vargas com respeito à participação eleitoral consiste no aumento do comparecimento. Esse dado reflete a atuação das máquinas partidárias, que precisavam alistar e mobilizar amplamente os eleitores. Tanto os partidos dos interventores quanto os de oposição investiram na mobilização eleitoral. Qual, então, a outra explicação para o bom desempenho dos primeiros?

\section{GANHANDO A ELEIÇÃO: A FRAUDE ELEITORAL}

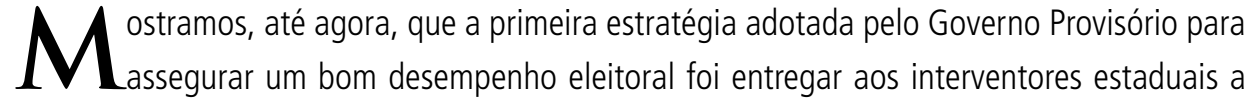
montagem dos novos partidos nos estados e cobrar deles a mobilização dos eleitores. Entretanto, como também as oposições estavam engajadas nesse processo e tinham as suas chances aumentadas com a adoção da representação proporcional pelo Código de 1932, tornava-se necessário recorrer a outros meios para garantir a vitória. Daqui em diante trataremos da segunda e mais decisiva das estratégias utilizadas pelo Governo Provisório para vencer 
nas urnas: a interferência dos partidos nas fases eleitorais, do alistamento até a contagem dos votos. A literatura tem qualificado como fraude eleitoral todo ato realizado pelos agentes legalmente encarregados de conduzir o processo eleitoral que viole as regras previstas para a realização das eleições, do alistamento até a diplomação dos eleitos (Schedler, 2002). Distanciando-se de uma visão normativa, que julga a fraude sob o aspecto de desvirtuamento da verdade eleitoral, a historiografia latino-americana mostrou o quanto tais práticas refletiam a disputa de poder no século XIX e nos princípios do século XX (Sabato, 2018). Na época, partidos disputavam o controle dos agentes encarregados de conduzir o processo eleitoral, como membros das comissões de alistamento, mesários, juízes locais etc., uma burocracia eleitoral também observada na Primeira República (Ricci e Zulini, 2017).

0 discurso reformista por trás da outorga do Código Eleitoral em 1932 apelava para a necessidade de combater essas práticas. Boa parte dos intérpretes que supôs a eficácia do Código na redução dos níveis fraude eleitoral destacou os papéis específicos de duas medidas combinadas como determinantes desse resultado: a adoção do voto secreto, paralelamente à criação da Justiça Eleitoral (Kinzo, 1980: 80; Sadek, 2010: 27). Contudo, experiências de outros países já mostraram que ambas as invenções não tiveram efeitos automáticos. 0 caso mexicano ilustra como a entrega da supervisão das eleições para órgãos judiciários não suplantou as interferências político-partidárias imediatamente (Eisenstadt, 2003). Também ficou provado que a adoção da cédula oficial de votação nos Estados Unidos visando tornar o voto secreto, ainda durante o século XIX, estimulou o surgimento de novas fraudes eleitorais: passou-se a pagar para os eleitores permanecerem em casa no dia da eleição, ao invés de pagar para fazê-los irem votar (Cox e Kousser, 1981).

Para verificar se os políticos encontraram novas formas de fraudar as eleições após 1932, sistematizamos as 886 alegações de fraude formalizadas contra as eleições de 1933 e publicadas pelos boletins do Tribunal Superior da Justiça Eleitoral, a instância responsável pelo julgamento de todos os recursos provenientes dos Tribunais Regionais Eleitorais ${ }^{8}$. Desse total, observamos dois padrões principais. 0 primeiro abarca 375 (42,3\%) alegações, referindo-se à inobservância de formalidades burocráticas, como omissões ou erros no registro de todos os procedimentos previstos no Código para se conduzir a eleição, a exemplo de ausência de assinaturas nos papéis eleitorais ou irregularidades na escolha dos mesários. As denúncias de violação do segredo do voto representam o segundo padrão, que engloba 363 (41\%) das alegações de fraude ${ }^{9}$.

Essas denúncias de violação do segredo do voto são o melhor reflexo da adaptação dos políticos às novas regras. 0 Código Eleitoral de 1932 não encarregou o governo da produção e distribuição de um modelo padrão de cédula oficial. A produção e a distribuição 
das cédulas aos eleitores continuavam a cargo dos próprios partidos políticos, resultando em tamanhos e formatos diferentes, facilmente identificáveis. Para contornar o problema e assegurar o segredo do voto na seção eleitoral, o Código estabeleceu a existência de um espaço fechado (denominado de cabine indevassável) onde o eleitor entraria, a sós, para inserir a cédula eleitoral do seu partido no envelope oficial opaco (a chamada sobrecarta) oferecido e numerado (seriado de 0 a 9) pelo mesário. Como todo eleitor precisava assinar a lista de presença da seção, que era sequencial, a numeração seriada das sobrecartas permitia ao mesário ter controle do número de sobrecartas por ele distribuído sem, porém, conseguir reconstituir a votação de cada eleitor. As alegações de fraude que denunciam a violação do voto secreto enfatizam quatro desvios principais às regras. 0 mais citado é a não correspondência entre o número de sobrecartas encontradas na urna e o número de votantes consignado na ata da seção eleitoral, alvo de 151 alegações de fraude relativas a 15 estados, além do Distrito Federal. Na sequência, destacam-se 95 denúncias, distribuídas entre 13 estados, quanto à numeração ou rubrica irregulares das sobrecartas. Impugnou-se, por exemplo, a eleição em uma seção de Curralinho, no Pará,

porque, efetivamente, as sobrecartas foram a princípio numeradas seguidamente, e depois, riscados os números, numeradas em séries. Ainda mais, acompanhando a urna, veio uma folha de votação, sem ser enviada pelo juiz, da qual consta a numeração seguida dos eleitores que votaram, coincidindo assim a numeração das sobrecartas com a lista referida, ocasionando, portanto, a violação do sigilo do voto (Tribunal Superior Eleitoral, 1933: 2567).

Em terceiro lugar, encontram-se 77 denúncias de violação do voto secreto relacionadas a problemas na remessa dos papéis eleitorais ou das próprias urnas aos tribunais regionais. Por fim, o último desvio principal às regras criadas para instituir o voto secreto aparece em 36 alegações de fraude que apontam o uso de sobrecartas fora dos padrões previstos pelo Código. Os casos mais extremos acusavam desde o emprego de sobrecartas de cores e dimensões diversas, a exemplo do que se passou em Minas Gerais, segundo o relato de um candidato sem partido, até o uso de sobrecartas não opacas, como os fiscais na Legião Autonomista Acreana denunciavam ter ocorrido em algumas seções de Juruá ${ }^{10}$. No Espírito Santo, o Tribunal Superior julgou procedente o protesto do Partido da Lavoura e anulou as eleições capixabas por se valerem de sobrecartas "transparentes ou translúcidas, violando de modo inequívoco o sigilo absoluto do voto, decorrendo daí a coação sobre o eleitorado" (Tribunal Superior Eleitoral, 1933: 2581). O Partido Evolucionista, em Santa Catarina, conseguiu o mesmo feito com a anulação das eleições no estado por causa de sobrecartas não suficientemente opacas. Aliás, uma perícia encomendada pelo Tribunal Superior da Justiça Eleitoral constatou a maior transparência das sobrecartas utilizadas no estado de Pernambuco comparadas às do 
caso capixaba (Correio da Manhã, 1933h: 2). Nem por isso, porém, as eleições pernambucanas foram anuladas. Tudo considerado, há evidências suficientes de que a fraude eleitoral continuava fazendo parte da competição política na Era Vargas ${ }^{11}$.

\section{IMPLICAÇÕES}

$\mathrm{T}$ da análise de marcos históricos corre o risco de reproduzir a narrativa que os catapultou a uma posição de destaque na memória coletiva. A interpretação do Código Eleitoral de 1932 é prova disso. Como se tratou de uma reforma ampla, que instituiu boa parte dos atuais pilares da democracia representativa brasileira, a literatura tende a reconhecer nas novas regras eleitorais o compromisso dos revolucionários de 1930 com aquele persuasivo discurso sobre a necessidade de moralizar os costumes políticos e o eleva ao posto de divisor de águas na trajetória do país rumo à democracia. Retomando, porém, a dubiedade do processo que levou à outorga do Código em 1932 e os resultados das eleições de 1933 e 1934, emerge a conveniência da reforma eleitoral para as elites revolucionárias legitimarem o novo regime. A adoção do Código, com reformas tão abrangentes, representou uma resposta dos revolucionários a quem questionava a legitimidade da Primeira República por causa da fraude eleitoral generalizada e da baixa participação popular. Na prática, porém, a democracia eleitoral não estava em pauta (Ricci, 2019). 0 Governo Provisório manteve-se focado em assegurar a vitória da Revolução nas urnas e afastou a possibilidade da incerteza dos resultados eleitorais instruindo a organização de partidos políticos pelos interventores e, em último caso, admitindo o recurso à fraude. Em linha com as experiências de outros autoritarismos eleitorais, buscava-se "o princípio do consentimento popular, mesmo que o subvertam na prática" (Schedler, 2006: 121, tradução nossa). Do ponto de vista dos resultados eleitorais, tudo correu de forma conveniente ao regime. Para o pesquisador, torna-se crucial entender o que aconteceu após a outorga do Código, tendo em vista as eleições de 1933. Precisamos ter cuidado com os momentos preparatórios que antecedem a primeira eleição pós-revolucionária. Vários atores entram em cena. Partidos, interventores, organizações sindicais, a Igreja Católica, velhos oligarcas; todos eles deveriam ser levados em conta neste processo de reconstrução das alianças políticas estaduais.

Há dois desdobramentos importantes para futuras pesquisas. Em primeiro lugar, cabe repensar o papel dos partidos políticos antes da 1945. O estudo das eleições na Era Vargas desvenda o protagonismo dos partidos em alistar eleitores, distribuir cédulas e instruí-los a votar. Quando os partidos foram omissos nessa tarefa, o governo perdeu a eleição. Isso significa que a questão se tornou a de mobilizar um contingente eleitoral cada vez 
maior. Resta entender melhor quem dos partidos dos interventores exerceu essa tarefa na prática, e que provavelmente não se fiava apenas na figura do coronel ou do chefe político local. Também importa compreender as oposições que ganham em 1933 e 1934 . Quais as suas estratégias?

O segundo desdobramento é sobre a fraude eleitoral. Já é tempo de pensá-la para além do tema do desvirtuamento da verdade eleitoral e associá-la a um mecanismo de competição política. Estudos recentes sobre as eleições na Primeira República têm evidenciado que a fraude escondia um jogo complexo e articulado entre os vários componentes da burocracia eleitoral encarregada de conduzir as eleições. No limite, a fraude eleitoral constituía a sine qua non da competição política (Ricci e Zulini, 2017). A análise das eleições no Brasil da Era Vargas mostrou uma readaptação dos mecanismos usados pelos partidos para ganhar as eleições. Não adianta bradar os aspectos formais do Código e desconsiderar a atuação dos agentes políticos naquelas eleições.

\section{NOTAS}

1 Um balanço do estado da arte sobre a política na Primeira República encontra-se em Ferreira e Pinto (2017).

2 Sabe-se das várias subdivisões existentes no movimento tenentista (Carvalho, 2005; Conniff, 1979; Drummond, 1986). Para os propósitos deste trabalho cabe apenas frisar que os tenentistas tinham prioridades diferentes daquelas das elites políticas estaduais.

3 A cédula oficial de votação para as eleições presidenciais foi aplicada apenas em 1955. Antes disso, os próprios partidos ficavam encarregados de fabricá-las e distribuí-las aos eleitores. 4 Decreto $n^{\circ}$ 21.402, de 14 de maio de 1932 (BRASIL, 1932).

5 Diário da Manhã (PE), Edição n. 1764, "A agitação em torno do pleito de maio", 16/02/1933, p. 1. A esses dois casos poderíamos acrescentar o do Rio Grande do Sul, onde a atuação de Flores da Cunha foi fundamental na criação e organização do Partido Republicano Liberal (PRL). Para uma análise da atuação do partido nas eleições de 1933, ver, por último, Lapuente (2018) e Rangel (2001).

6 A organização da LEC, os atores envolvidos na construção do partido, assim como as práticas eleitorais entre 1933 e 1934, foram analisados recentemente na dissertação de Janilson Rodrigues Lima (2020).

70 significado de oposição no contexto pós-revolução não equivale a um posicionamento expresso contra o Governo Provisório. Poucos partidos vocalizaram um discurso reacionário, como se passou em Goiás, com os Caiados promovendo o Partido Democrático; na Bahia, 
com João Seabra lançando a coligação "A Bahia ainda é a Bahia", e em São Paulo, com a Chapa Única formada pela fusão de antigos membros do Partido Republicano Paulista com os integrantes do Partido Democrático.

8 A fonte traz recursos contra as eleições em todos os estados, à exceção da Paraíba, por motivo desconhecido.

9 Os demais casos referem desde alegações de fraude no alistamento até apuração parcial das eleições.

10 Ver Boletim Eleitoral, n. 127, de 30 de agosto de 1933, p. 2615, e n. 141, de 18 outubro de 1933, p. 2838.

11 Outra fonte confirma essa visão. A análise de 42 notícias veiculadas pelos jornais nos primeiros 30 dias após o pleito de maio de 1933 revela que as expectativas sobre o voto secreto foram frustradas. Apesar de alguns reconhecerem os avanços do Código, avaliava-se que 0 voto secreto fora amplamente violado, fosse pela violência, coação generalizada, fosse pelo uso de estratagemas específicos, como cédulas em papel cartolina, sobrecartas transparentes e até ausência da cabine indevassável. Essas noticias encontram-se nos seguintes jornais: Diario de Notícias (1933a, 1933b, 1933c, 1933d, 1933e, 1933g, 1933h, 1933j), Correio da Manhã (1933b, 1933c, 1933d, 1933e, 1933f, 1933g), A Batalha (1933a, 1933b, 1933c, 1933d, 1933e), A Noite (1933), Jornal de Recife (1933a, 1933b, 1933c, 1933d, 1933e), A Federação (1933a, 1933b), Diario Carioca (1933a, 1933b, 1933c), O Radical (1933b, 1933c), A República (1933), Correio de São Paulo (1933), Diário da Noite (1933a, 1933b, 1933c).

\section{FONTES DOCUMENTAIS}

A BATALHA. A dolorosa certeza. A Batalha, n. 991, p. 2, 23 de maio de 1933a.

A BATALHA. Fogueles prematuros. A Batalha, n. 979, p. 3, 9 maio 1933b.

A BATALHA. Impõe-se a anulação do pleito de 3 de Maio, no Espirito Santo, pela violação do sigillo do voto. A Batalha, n. 999, p. 1, $1^{\circ}$ jun. 1933c.

A BATALHA. 0 pleito do dia 3, em Minas, esteve á altura dos processos antigos. A Batalha, n. 985, p. 1, 16 maio 1933d.

A BATALHA. Para a formação da Assembleia Constituinte. A Batalha, n. 975, p. 2, 4 maio 1933 e.

A FEDERAÇÃO. Mais um "traidor". A Federação, n. 106, p. 1, 6 maio 1933 a.

A FEDERAÇÃO. Meu cantinho. A Federação, n. 108, p. 3, 9 maio 1933b.

A FEDERAÇÃO. Rumo a constitucionalização. A Federação, n. 23, p. 3, 27 jan. 1932. 
A NOITE. A caminho da constitucionalização. A Noite, Rio de Janeiro, n. 23, p. 1, 23 jan. 1932.

A NOITE. Feriu-se hontem, em todo o paiz, um dos mais memoráveis pleitos da historia da Republica. A Noite, n. 7.700, p. 1, 4 maio 1933.

A REPÚBLICA. 7 maio 1933.

CORREIO DA MANHÃ. A reforma eleitoral. Correio da Manhã, Rio de Janeiro, n. 11.386, p. 4, 24 jan. 1932.

CORREIO DA MANHÃ. A situação política. Correio da Manhã, Rio de Janeiro, n. 11.359, p. 1, 24 dez. 1931 a. CORREIO DA MANHÃ. Constituída a "União Cívica Brasileira". Correio da Manhã, Rio de Janeiro, n. 11.721, p. 3, 18 fev. 1933a.

CORREIO DA MANHÃ. Liberdade de voto na saúde publica. Correio da Manhã, n. 11.783, p. 1, 3 maio 1933b. CORREIO DA MANHÃ. O homem da chapa eclectica. Correio da Manhã, n. 11.792, p. 2, 13 maio 1933c.

CORREIO DA MANHÃ. 0 pleito de 3 de Maio. Correio da Manhã, n. 11.788, p. 1, 9 maio 1933d.

CORREIO DA MANHÃ. O pleito em Campinas. Correio da Manhã, n. 11.786, p. 3, 6 maio 1933 e.

CORREIO DA MANHÃ. Originalidade originalíssima. Correio da Manhã, Rio de Janeiro, n. 11.282, p. 4, 25 set. 1931b. CORREIO DA MANHÃ. Politica da Parahyba. Correio da Manhã, n. 11.797, p. 4, 19 maio $1933 f$.

CORREIO DA MANHÃ. Uma importante decisão do Supremo Tribunal Superior Eleitoral. Correio da Manhã, Rio de Janeiro, n. 11.897, p. 2, 13 set. 1933h.

CORREIO DA MANHÃ. Voto secreto. Correio da Manhã, n. 11.795, p. 4, 17 maio $1933 \mathrm{~g}$.

CORREIO DE SÃO PAULO. Contrastes e confrontos. Correio de São Paulo, n. 280, p. 3, 10 maio 1933.

DIARIO CARIOCA. As irregularidades do pleito no Espirito Santo. Diario Carioca, n. 1.475, p. 1, 28 maio $1933 a$.

DIARIO CARIOCA. 0 pleito nos estados. Diario Carioca, n. 1.457, p. 6, 7 maio 1933b.

DIARIO CARIOCA. Virtudes e surpresas. Diario Carioca, n. 1.467, p. 6, 19 maio 1933c.

DIÁRIO DA MANHÃ. A agitação em torno do pleito de maio. Diário da Manhã, Pernambuco, n. 1.764, p. 1, 16 fev. 1933.

DIÁRIO DA NOITE. A sessão de hoje do Tribunal Superior de Justiça Eleitoral. Diario da Noite, n. 929, p. 1, 12 maio 1933a.

DIÁRIO DA NOITE. Cataguazes num regime de inquietação e de insegurança pessoal. Diario da Noite, n. 943 p. 3, 29 maio 1933b.

DIÁRIO DA NOITE. Isto é que é. Diario da Noite, n. 927, p. 2, 10 maio 1933c.

DIÁRIO DA NOITE. Política baiana. Diário da Noite, Rio de Janeiro, n. 842, 3. ed., p. 12, 26 jan. 1933 d.

DIARIO DE NOTÍCIAS. A experiencia satisfatoria do voto secreto. Diario de Noticias, Rio de Janeiro, n. 1041, p. 3, 5 maio 1933a. 
DIARIO DE NOTÍCIAS. Afim de apressar a apuração no pleito. Diario de Noticias, Rio de Janeiro, n. 1.046, p. 6, 10 maio $1933 \mathrm{~b}$.

DIARIO DE NOTíCIAS. As eleições na Parahyba e a actuação do sr. José Americo. Diario de Noticias, Rio de Janeiro, n. 1.057, p. 1, 21 maio 1933c.

DIARIO DE NOTíCIAS. O soberano é o povo. Diario de Noticias, Rio de Janeiro, n. 1.053, p. 6, 17 maio 1933d. DIARIO DE NOTÍCIAS. Ouvindo o constituinte mais votado em Pernambuco. Diario de Noticias, Rio de Janeiro, n. 10.59 , p. 1, 23 maio 1933 e.

DIARIO DE NOTíCIAS. Panorama político. Diario de Noticias, Rio de Janeiro, n. 933, p. 2, 15 jan. $1933 f$.

DIARIO DE NOTÍCIAS. Para Todos. Diario de Noticias, Rio de Janeiro, n. 1.039, p. 3, 3 maio 1933g.

DIARIO DE NOTÍCIAS. Para Todos. Diario de Noticias, Rio de Janeiro, n. 1.042, p. 3, 6 maio 1933h.

DIARIO DE NOTíCIAS. Política. Diário de Notícias, Rio de Janeiro, n. 972, p. 3, 23 fev. 1933 i.

DIARIO DE NOTíCIAS. Sete dias de política. Diario de Noticias, Rio de Janeiro, . 1043, p. 2, 7 maio 1933j.

DIÁRIO DO CONGRESSO NACIONAL, 21 maio 1930.

JORNAL DO RECIFE. A situação politica no Rio Grande do Norte. Jornal do Recife, n. 105, p. 1, 10 maio 1933 a.

JORNAL DO RECIFE. As eleições procedidas no dia 3 de maio. Jornal do Recife, n. 101, p. 1, 5 maio 1933b.

JORNAL DO RECIFE. Entrevista obtida de quem não poderia fornece-la. Jornal do Recife, n. 115, p. 3, 21 maio 1933C.

JORNAL DO RECIFE. Reflexões sobre o ultimo pleito eleitoral. Jornal do Recife, n. 110, p. 1, 16 maio 1933d. JORNAL DO RECIFE. Unidos venceriam. Jornal do Recife, n. 107, p. 1, 12 maio 1933 e.

JORNAL DO BRASIL. Ainda o anteprojeto eleitoral. Jornal do Brasil, Rio de Janeiro, n. 265, p. 5, 6 nov. 1931. JORNAL DO BRASIL. 0 interventor Maynard Gomes está alheio à formação de partidos políticos. Jornal do Brasil, Rio de Janeiro, p. 8, 31 mar. 1933.

JORNAL DO COMÉRCIO. A convenção liberal. Jornal do Comércio, Rio de Janeiro, n. 226, p. 4, 21 set. 1929. JORNAL DO COMÉRCIO. A situação. Jornal do Comércio, Rio de Janeiro, n. 41, p. 4, 17 fev. 1933.

O IMPARCIAL. Partido Revolucionário Maranhense. O Imparcial, Maranhão, n. 2.787, p. 1, 31 out. 1931. O MALHO. Rio de Janeiro, n. 1.117, p. 45, 9 fev. 1924.

O RADICAL. Política e politicagem. O Radical, Rio de Janeiro, n. 230, p. 12, 27 jan. 1933a.

O RADICAL. Em torno do grande pleito constitucional. O Radical, n. 326, p. 1, 7 maio 1933b.

O RADICAL. Telegramas recebidos pelo Ministro da Justiça. O Radical, n. 335, p. 1, 18 maio 1933c.

TRIBUNAL SUPERIOR ELEITORAL. Boletim Eleitoral, n. 124, 19 ago. 1933, p. 2581. 
TRIBUNAL SUPERIOR ELEITORAL. Boletim Eleitoral, n. 127, 30 ago. 1933, p. 2615.

TRIBUNAL SUPERIOR ELEITORAL. Boletim Eleitoral, n. 141, 18 out. 1933, p. 2581.

\section{REFERÊNCIAS BIBLIOGRÁFICAS}

ASSIS BRASIL, Joaquim F. Democracia representativa: do voto e do modo de votar. Rio de Janeiro: Typ. de G. Leuzinger, 1893.

BRASIL. Decreto $n^{\circ} 21.402$, de 14 de maio de 1932. Brasil, 1932. Disponível em: <http://www.planalto.gov. br/ccivil_03/decreto/1930-1949/D21402.htm>. Acesso em: 19 ago. 2020.

CABRAL, João C. R. Systemas eleitoraes do ponto de vista da representação proporcional das minorias. Imprenta: Rio de Janeiro, F. Alves, 1929.

CARVALHO, José M. Forças Armadas e política no Brasil. Rio de Janeiro: Jorge Zahar, 2005.

CONNIFF, Michael. Os tenentes no poder: uma nova perspectiva da Revolução de 30. In: FIGUEIREDO, Eurico L. (org.). Os militares e a Revolução de 30. Rio de Janeiro: Paz e Terra, 1979.

COX, Gary W.; KOUSSER, J. M. Turnout and rural corruption: New York as a test case. American Journal of Political Science, v. 25, n. 4, p. 646-663, 1981. http://doi.org/10.2307/2110757

DRUMMOND, José A. O movimento tenentista: intervenção militar e conflito hierárquico (1922-1935). Rio de Janeiro: Graal, 1986.

EISENSTADT, Todd A. Courting democracy in Mexico: party strategies and electoral institutions. Cambridge: Cambridge University Press, 2003.

FERREIRA, Marieta M.; PINTO, Surama C. S. Estado e oligarquias na Primeira República: um balanço das principais tendências historiográficas. Tempo, Niterói, v. 23, n. 3, p. 422-442, 2017. http://doi.org/10.1590/ TEM-1980-542X2017v230301

GANDHI, Jennifer. Political Institutions under Dictatorship. Nova York: Cambridge University Press, 2009.

GOMES, Angela de C. Introdução. In: GOMES, Angela C. et al. (coords.). Regionalismo e centralização política: partidos e Constituinte nos anos 30. Rio de Janeiro: Nova Fronteira, 1980. p. 23-131.

GOMES, Angela de C.; ABREU, Marta. A nova "Velha" República: um pouco de história e historiografia. Apresentação. Revista Tempo, Niterói, v. 13, n. 26, p. 1-14, 2009.

KINZO, Maria D. G. Representação política e sistema eleitoral no Brasil. São Paulo: Edições Símbolo, 1980.

LAMOUNIER, Bolívar. Da independência a Lula: dois séculos de política brasileira. São Paulo: Angurium, 2005.

LAPUENTE, Rafael S. Sob a espada Dâmocles: as eleições de 1933 no Rio Grande do Sul-entre o exílio, repressão e conspiração. Antíteses, v. 11, n. 21, p. 267-287, 2018. http://dx.doi.org/10.5433/1984$3356.2018 \mathrm{v} 11 \mathrm{n} 21 \mathrm{p} 267$

LEAL, Victor Nunes. Coronelismo, enxada e voto 3. ed. Rio de Janeiro: Nova Fronteira, 1997.

LE GOFF, Jacques. História e memória. Campinas: Ed. da Unicamp, 1990. 
LIMA, Janilson Rodrigues. A Liga Eleitoral Católica é partido político?: A LEC e as eleições no Ceará CEARÁ (1933-1934). Dissertação (Mestrado em História) - Universidade Federal do Estado do Rio de Janeiro, Rio de Janeiro, 2020.

LOPES, Raimundo H. O poder discricionário: ditadura e constitucionalização no Governo Provisório. In: RICCI, Paolo (org.). 0 autoritarismo eleitoral dos anos trinta e o código eleitoral de 1932. Curitiba: Appris, 2019. p. 19-40.

MORGENBESSER, Lee. Elections in Hybrid Regimes: Conceptual Stretching Revived. Political Studies, v. 62, n. 1, p. 21-36, 2014. https://doi.org/10.1111\%2F1467-9248.12020

NICOLAU, Jairo. Eleições no Brasil: do Império aos dias atuais. Rio de Janeiro: Zahar, 2012.

PANDOLFI, Dulce C. A trajetória do Norte: uma tentativa de ascensão política. In: GOMES, Angela C. et al. (coords.). Regionalismo e centralização política: partidos e Constituinte nos anos 30. Rio de Janeiro: Nova Fronteira, 1980. p. 339-425.

PINTO, Celí R. J. Uma história do feminismo no Brasil. São Paulo: Fundação Perseu Abramo, 2003.

RANGEL, Carlos Roberto da Rosa. Crime e castigo: conflitos políticos no Rio Grande do Sul (1928-1938). Passo Fundo: UPF Editora, 2001.

RICCI, Paolo. 0 autoritarismo eleitoral dos anos trinta e o código eleitoral de 1932. Curitiba: Appris, 2019.

RICCI, Paolo; ZULINI, Jaqueline P. The Meaning of Electoral Fraud in Oligarchic Regimes: Lessons from the Brazilian Case (1899-1930). Journal of Latin American Studies, v. 49, n. 2, p. 243-268, 2017. https://doi. org/10.1017/S0022216X16001371

RICCI, Paolo; ZULINI, Jaqueline P. Partidos, competição política e fraude eleitoral: a tônica das eleições na Primeira República. Dados, Rio de Janeiro, v. 57, n. 2, p. 443-479, 2014. http://dx.doi.org/10.1590/00115258201414

SABATO, Hilda. Republics of the new world: the revolutionary political experiment in nineteenth-century Latin America. Princeton: Princeton University Press, 2018.

SADEK, Maria T. A justiça eleitoral e a consolidação da democracia no Brasil. Rio de Janeiro: Centro Edelstein de Pesquisas Sociais, 2010.

SCHEDLER, Andreas. Electoral Authoritarianism: the dynamics of unfree competition. CO: Lynne Rienner, 2006.

SCHEDLER, Andreas. The menu of manipulation. Journal of Democracy, v. 13, n. 2, p. 36-50, 2002. https:// doi.org/10.1353/jod.2002.0031

SCHWARCZ, Lilia M.; STARLING, Heloisa M. Brasil: uma biografia. São Paulo: Companhia das Letras, 2015.

SCHLEGEL, Rogerio; NÓBREGA, Josué. Qual voto secreto? 0 Código Eleitoral de 1932 e as transformações no sigilo do voto. In: RICCl, Paolo (org.). O autoritarismo eleitoral dos anos trinta e o código eleitoral de 1932. Curitiba: Appris, 2019. p. 83-108.

SERVA, Mário P. O voto secreto ou a organização de Partidos Nacionaes. Liga Nacionalista. São Paulo: Imprensa Methodista, 1927. 